\title{
Bcl-2 expression is altered with ovarian tumor progression: an immunohistochemical evaluation
}

\author{
Nicole S Anderson ${ }^{1}$, Leslie Turner ${ }^{1}$, Sandra Livingston ${ }^{1}$, Ren Chen ${ }^{2}$, \\ Santo V Nicosia ${ }^{1,3}$ and Patricia A Kruk*1,3
}

\begin{abstract}
Address: ${ }^{1}$ Department of Pathology and Cell Biology, University of South Florida, Tampa, FL 33612, USA, ${ }^{2}$ Office of Clinical Research, University of South Florida, Tampa, FL 33612, USA and ${ }^{3} \mathrm{H}$. Lee Moffitt Cancer Center and Research Institute, Tampa, FL 33612, USA

Email: Nicole S Anderson - nanderso@health.usf.edu; Leslie Turner - lpassmor@health.usf.edu; Sandra Livingston - slivings@health.usf.edu; Ren Chen - rchen@ health.usf.edu; Santo V Nicosia - snicosia@ health.usf.edu; Patricia A Kruk* - pkruk@ health.usf.edu

* Corresponding author
\end{abstract}

Published: 25 October 2009

Journal of Ovarian Research 2009, 2:16 doi:10.1 I86/1757-2215-2-16

Received: 19 June 2009

Accepted: 25 October 2009

This article is available from: http://www.ovarianresearch.com/content/2/1/16

(C) 2009 Anderson et al; licensee BioMed Central Ltd.

This is an Open Access article distributed under the terms of the Creative Commons Attribution License (http://creativecommons.org/licenses/by/2.0),

which permits unrestricted use, distribution, and reproduction in any medium, provided the original work is properly cited.

\begin{abstract}
Background: Ovarian cancer is the most lethal gynecologic malignancy. The ovarian tumor microenvironment is comprised of tumor cells, surrounding stroma, and circulating lymphocytes, an important component of the immune response, in tumors. Previous reports have shown that the anti-apoptotic protein $\mathrm{Bcl}-2$ is overexpressed in many solid neoplasms, including ovarian cancers, and contributes to neoplastic transformation and drug-resistant disease, resulting in poor clinical outcome. Likewise, studies indicate improved clinical outcome with increased presence of lymphocytes. Therefore, we sought to examine $\mathrm{Bcl}-2$ expression in normal, benign, and cancerous ovarian tissues to determine the potential relationship between epithelial and stromal $\mathrm{Bcl}-2$ expression in conjunction with the presence of lymphocytes for epithelial ovarian tumor progression.
\end{abstract}

Methods: Ovarian tissue sections were classified as normal $(n=2)$, benign $(n=17)$ or cancerous $(n=28)$ and immunohistochemically stained for $\mathrm{Bcl}-2$. Bcl-2 expression was assessed according to cellular localization, extent, and intensity of staining. The number of lymphocyte nests as well as the number of lymphocytes within these nests was counted.

Results: While $\mathrm{Bcl}-2$ staining remained cytoplasmic, both percent and intensity of epithelial and stromal $\mathrm{Bcl}-2$ staining decreased with tumor progression. Further, the number of lymphocyte nests dramatically increased with tumor progression.

Conclusion: The data suggest alterations in $\mathrm{Bcl}-2$ expression and lymphocyte infiltration correlate with epithelial ovarian cancer progression. Consequently, Bcl-2 expression and lymphocyte status may be important for prognostic outcome or useful targets for therapeutic intervention.

\section{Background}

Ovarian cancer (OC) currently ranks $5^{\text {th }}$ in cancer related deaths among women in the United States [1] in spite of advances in treatment. Despite an overall OC survival rate of $45 \%$, the five year survival rate for women diagnosed with OC in its early stages is $94 \%$, however these women only make up $19 \%$ of reported OC cases [2]. This poor prognosis is, in part, due to a lack of symptoms at early 
stages as well as lack of a screening marker available to the general public. The ovarian surface epithelium is generally believed to be the origin for the majority of epithelial ovarian cancer cases [3], though current reports of a fallopian tube origin for ovarian cancer have emerged [4,5]. Consequently, the etiology of ovarian cancer is still poorly understood.

A basement membrane consisting mainly of collagenous connective tissue separates the ovarian surface epithelium (OSE), a modified mesothelium, from underlying ovarian stromal tissue [6]. The OSE and stroma both synthesize and secrete components that contribute to deposition of the basement membrane during postovulatory repair [7]. Normal ovarian stroma also produces an array of growth factors, including, but not limited to transforming growth factor- $\beta_{1}$ (TGF- $\left.\beta_{1}\right)$ and the hepatocyte growth factor (HGF) receptor c-Met that stimulate autocrine and paracrine-mediated proliferation of the superjacent epithelium. These growth factors tend to be overexpressed in many carcinomas, hence facilitating neoplastic growth [8]. Additionally, stromal-epithelial interactions have been studied in cancers of the bladder, breast, cervix, colon, prostate, and ovary [9-14] and have shown that stromal cells influence epithelial cell growth as well as tumorigenesis.

In addition to the role of the tumor microenvironment, alterations in apoptotic regulation promoting an antiapoptotic phenotype also support tumor progression. Specifically, Bcl-2, recognized as the prototypical antiapoptotic protein, is overexpressed in a number of solid tumors, including ovarian cancer, and contributes to neoplastic transformation through inhibition of apoptosis [15], thereby promoting tumor survival.

In contrast, ovarian tumors can also elicit a marked host immune response resulting in the influx of tumor infiltrating lymphocytes into the tumor which recognize antigens expressed on ovarian tumors [16]. The presence of tumor infiltrating lymphocytes in ovarian cancer patients appears to confer a survival advantage [17-19]; however, this immune response is not normally sufficient to inhibit tumor growth over extended periods of time.

While several studies have previously examined Bcl-2 or the contribution of tumor infiltrating lymphocytes separately for ovarian cancer prognosis, we sought to further determine the combined clinical relationship between Bcl-2 expression and lymphocyte filtration for ovarian cancer progression. To our knowledge there have not been any other similar studies to date. Therefore, given the close proximity of tumor cells, their surrounding stroma, and infiltrating lymphocytes, we analyzed the immunohistochemical expression and histological localization of
Bcl-2 in ovarian the stromal and epithelial components of normal, benign, and cancer clinical specimens as well as evaluated changes in lymphocyte populations with ovarian tumor progression.

\section{Methods \\ Tissue Specimens}

With institutional approval, a previously existing tissue bank was utilized to retrieve a cohort of de-identified women who had undergone primary surgery with complete surgical staging for epithelial ovarian cancer or borderline tumors at the $\mathrm{H}$. Lee Moffitt Cancer Center between 2000 and 2001. This gynecologic oncology procedure database was also used to select women who had undergone oophrectomy due to cystadenoma or had their ovaries removed for unrelated pathology between 2000 and 2001. All tissue specimens were fixed with $10 \%$ formalin and paraffin-embedded. Four micron sections were stained with haematoxylin and eosin ( $\mathrm{H} \& \mathrm{E})$ and the slides were reviewed by a pathologist (SVN) to confirm histologic diagnosis according to the International Federation of Gynecology and Obstetrics (FIGO) classification system. The de-identified medical records of these women were reviewed, and tumor pathology was correlated to the immunohistochemical findings. From these observations, the selected ovarian sections were given the following classifications: 2 normal, 17 benign cysts or cystadenomas, and 28 serous papillary carcinomas, though areas of normal ovarian surface epithelium were also present in 5 benign and 4 carcinoma sections.

\section{Immunohistochemistry}

For immunohistochemical studies, further formalin-fixed paraffin sections were cut at 3 microns and dried overnight at room temperature then deparaffinized and rehydrated. Sections were soaked in hydrogen peroxide to block endogenous peroxidase activity. Microwave antigen retrieval was achieved by placing slides in $1 \times$ solution of AR-10 (BioGenex \#HK057-5K, San Ramon, CA), boiling, and then microwaving for an additional 10 minutes. The specimens were then immunostained on the Dako Autostainer (Dako North America, Inc., Carpinteria, CA) using Monoclonal Mouse Anti-Human Bcl-2 (Clone 124, Dako, Carpinteria, CA) primary antibody (1:40) for 30 minutes and the Dako's EnVision ${ }^{\mathrm{TM}}+$ HRP Mouse $(\mathrm{DAB}+)$ kit according to the manufacturer's instructions, then counterstained with modified Mayer's haematoxylin, dehydrated through graded alcohol, cleared with xylene, and mounted with resinous mounting medium. In an effort to control variability, all samples were stained at the same time and with the same lot of reagents. Normal tonsil was used as an internal positive control while negative controls were obtained by substitution of primary antibody with normal mouse serum. 


\section{Staining Analysis}

Immunohistochemical staining was evaluated independently by four authors (LP, NSA, PAK, and SVN). The pattern of Bcl-2 staining was evaluated as nuclear or cytoplasmic. Amount of stromal and epithelial staining was assessed as percent staining from each section and scored as having either $\leq 50 \%$ or $>50 \%$ positive cells. Staining intensity was also evaluated and classified as negative, weak, moderate, or intense staining. The presence of lymphocyte nests in each section was also observed and counted by observing assemblages of ten or more lymphocytes in 10 random viewings at a total magnification of $100 \times$. The number of lymphocytes in each observed nest was also counted and grouped into 5 categories: $<25$, $25-50,50-75,75-100$, or >100 lymphocytes per nest.

\section{Statistical Methods}

SAS version 9.2 (SAS Institute, Cary, NC) was used for statistical analysis of Bcl-2 staining in normal, benign, and cancerous tissue samples. Fisher's exact test was used to test for associations in extent of epithelial and stromal staining between tumor types and staining intensity of epithelial and stromal staining between tissue types. The Cochran-Mantel-Haenszel test was used to test for independence between tissue type and lymphocyte nest size. The generalized linear model, along with pair-wise comparison among tissue types was used to test for differences in tissue type and the number of lymphocyte nests present.

\section{Results}

Immunohistochemical staining was performed on a total of 47 ovarian tissue sections as characterized in table 1.
The mean age of the sample population was 62 years (range, 33-88 years) and no significant differences were noted in age among categories. The predominant histologic type for malignant tissue samples was serous (26/ 28 ), and patients typically presented with high grade tumors (Grade 3, 19/28). The majority of the malignant samples were also from patients with stage III ovarian cancer (25/28). Samples classified as "other" included follicular cysts and a cystadenofibroma.

All tissues in this study, with the exception of four poorly differentiated serous papillary carcinomas, displayed some degree of epithelial and/or stromal Bcl-2 staining. Bcl-2 staining was confined to the cytoplasm in epithelial and stromal cells. While only 2 specimens were classified as normal, there were areas of normal epithelia on 5 benign and 4 cancerous specimens. Due to the small number of normal specimens we were able to procure, we included these additional areas in our normal epithelial analyses. Epithelial Bcl-2 staining was present in 91\% (10/ 11) normal, $100 \%$ (17/17) benign, and 79\% (22/28) cancer specimens (Figure 1, Table 2). Further, 65\% (11/17) benign specimens showed epithelial Bcl-2 staining in more than $50 \%$ of their epithelial cells, whereas, $18 \%$ (2/ 11 ) and $29 \%(8 / 28)$ normal and ovarian cancer tissues, respectively, displayed epithelial $\mathrm{Bcl}-2$ staining to the same extent (Table 2). In the cancerous sections, extent of $\mathrm{Bcl}-2$ epithelial staining tended to decrease with increased tumor grade (Table 2, Figure 2). More than $50 \%$ of the epithelial cells stained positive for Bcl-2 in $67 \%(2 / 3)$ of well differentiated carcinomas (WD), 33\% (2/6) of moderately differentiated serous papillary carcinomas (MD), and $21 \%(4 / 19)$ of poorly differentiated serous papillary

Table I: Characteristics of the study cohort.

\begin{tabular}{|c|c|c|c|c|c|c|}
\hline & $\begin{array}{l}\text { Normal } \\
(n=2)\end{array}$ & $\begin{array}{l}\text { Cysts } \\
(n=4)\end{array}$ & $\begin{array}{l}\text { Cystadenomas } \\
(n=13)\end{array}$ & $\begin{array}{l}\text { WD (Grade I) } \\
(\mathrm{n}=3)\end{array}$ & $\begin{array}{l}\text { MD (Grade 2) } \\
(n=6)\end{array}$ & $\begin{array}{l}\text { PD (Grade 3) } \\
(n=19)\end{array}$ \\
\hline \multicolumn{7}{|l|}{ Age (years) } \\
\hline Mean (SD) & $57.5(12.0)$ & $58.0(16.1)$ & $65.0(10.1)$ & $48.7(6.5)$ & $64.8(16.7)$ & $62.7(14.5)$ \\
\hline Range & $49-66$ & $48-81$ & $49-79$ & $42-55$ & $33-76$ & $33-88$ \\
\hline \multicolumn{7}{|l|}{ Histology } \\
\hline Serous & N/A & I & 11 & I & 6 & 19 \\
\hline Mucinous & $N / A$ & 0 & 1 & 0 & 0 & 0 \\
\hline Endometrioid & $N / A$ & 0 & 0 & 2 & 0 & 0 \\
\hline Other & $N / A$ & 3 & 1 & 0 & 0 & 0 \\
\hline \multicolumn{7}{|l|}{ Stage } \\
\hline 1 & $N / A$ & $N / A$ & N/A & 0 & 0 & 1 \\
\hline II & $N / A$ & $N / A$ & $N / A$ & I & 0 & 0 \\
\hline III & $\mathrm{N} / \mathrm{A}$ & $\mathrm{N} / \mathrm{A}$ & $\mathrm{N} / \mathrm{A}$ & 2 & 6 & 17 \\
\hline IV & $\mathrm{N} / \mathrm{A}$ & $N / A$ & $\mathrm{~N} / \mathrm{A}$ & 0 & 0 & 1 \\
\hline
\end{tabular}

N/A indicates category was not applicable to those samples.

$\mathrm{WD}=$ well differentiated carcinoma, $\mathrm{MD}=$ moderately differentiated serous papillary carcinoma, $\mathrm{PD}=$ poorly differentiated serous papillary carcinoma 
Table 2: Bcl-2 immunoreactivity in ovarian tissue sections.

\begin{tabular}{|c|c|c|c|c|c|c|c|}
\hline & \multirow[b]{2}{*}{ Total } & \multicolumn{3}{|c|}{ \% Positive Epithelium (n) } & \multicolumn{3}{|c|}{ \% Positive Stroma (n) } \\
\hline & & Total & $\leq \mathbf{5 0} \%$ & $>\mathbf{5 0} \%$ & Total & $\leq \mathbf{5 0} \%$ & $>\mathbf{5 0} \%$ \\
\hline Normal & 2 & $50(I)$ & $100(2)$ & 0 & $100(2)$ & 0 & $100(2)$ \\
\hline Normal within Benign & 5 & $100(5)$ & $100(5)$ & 0 & --- & --- & -- \\
\hline Normal within Cancer & 4 & $100(4)$ & $50(2)$ & $50(2)$ & --- & --- & --- \\
\hline Total Normal & II & $91(10)$ & $82(9)$ & $18(2)$ & $100(2)$ & 0 & $100(2)$ \\
\hline Cysts & 4 & $100(4)$ & $25(\mathrm{I})$ & $75(3)$ & $50(2)$ & $75(3)$ & $25(\mathrm{I})$ \\
\hline Cystadenomas & 13 & $100(13)$ & $38(5)$ & $62(8)$ & $92(12)$ & $62(8)$ & $38(5)$ \\
\hline Total Benign & 17 & $100(17)$ & $35(6)$ & 65 (II) & $82(14)$ & 65 (II) & $35(6)$ \\
\hline WD & 3 & $100(3)$ & $33(1)$ & $67(2)$ & $100(3)$ & $66(2)$ & $33(1)$ \\
\hline MD & 6 & $100(6)$ & $67(4)$ & $33(2)$ & $17(1)$ & $83(5)$ & $17(I)$ \\
\hline PD & 19 & $68(13)$ & 79 (I5) & $21(4)$ & $68(13)$ & $95(18)$ & $5(I)$ \\
\hline Total Cancerous & 28 & 79 (22) & $71(20)$ & $29(8)$ & $61(17)$ & $89(25)$ & II (3) \\
\hline
\end{tabular}

WD = well differentiated carcinoma, $M D=$ moderately differentiated serous papillary carcinoma, $P D=$ poorly differentiated serous papillary carcinoma

carcinomas (PD) (Table 2, Figure 2). Though there was a trend, these differences were not statistically significant. Similar to the extent of staining, intensity of epithelial Bcl2 staining was higher in benign samples, with 94\% (16/ 17) of benign sections showing an intensity of moderate or intense, while $64 \%(7 / 11)$ and $43 \%(12 / 28)$ normal and malignant sections, respectively, showed an epithelial staining intensity of moderate or intense degree (Figure 3). More specifically, the epithelial staining intensity in cystadenomas was significantly higher than that in both $M D$ and $P D$ sections $(P=0.02$ and $P<0.0001$, respectively), but not in WD sections. Comparison among the cancerous samples showed that there was decreased epithelial Bcl-2 intensity with advanced tumor grade (Figure
3); however, these differences did not reach statistical significance.

Like epithelial staining, stromal Bcl-2 staining also decreased with malignant progression (Figure 4). One hundred percent (2/2) normal, 82\% (14/17) benign, and $61 \%(17 / 28)$ malignant samples stained positive for stromal Bcl-2 (Table 2). While 100\% (2/2) of the normal specimens were found to have a positive $\mathrm{Bcl}-2$ staining in more than $50 \%$ of the stromal cells, 35\% (6/17) of benign tumors had Bcl-2 expression in more than $50 \%$ of the stromal cells (Figure 5). In contrast, only $11 \%(3 / 28)$ of ovarian cancer sections had more than $50 \%$ of their stromal cells expressing Bcl-2 (Figure 5), and similar to extent

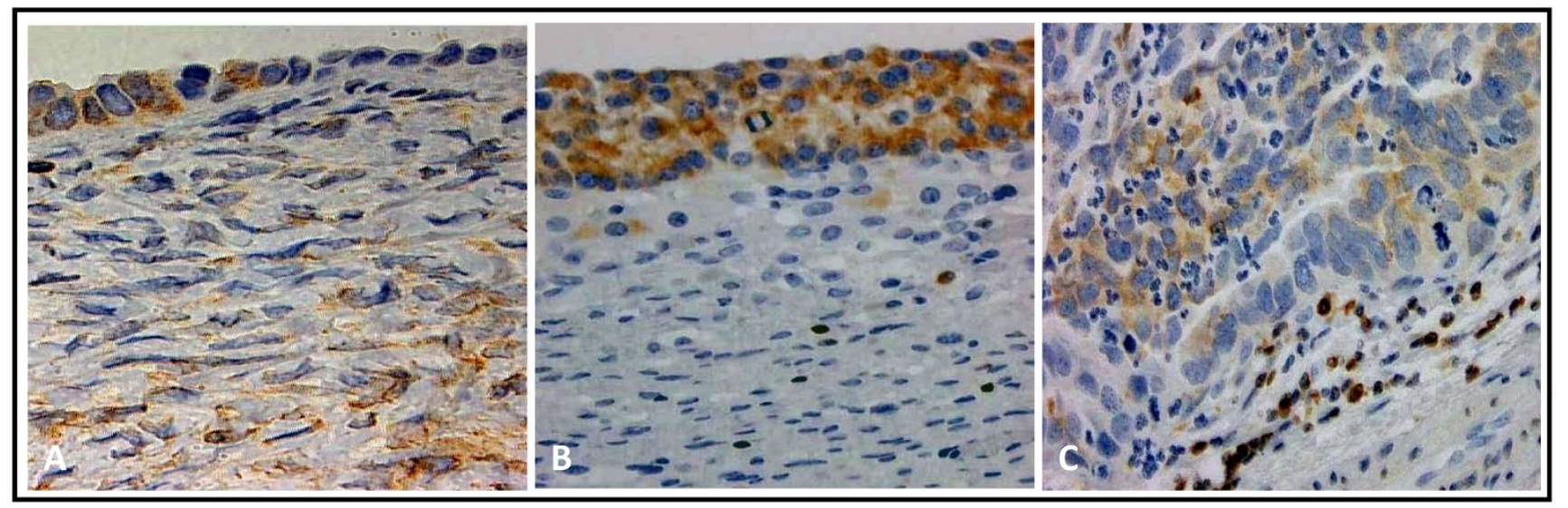

Figure I

Bcl-2 staining is most extensive in cysts. Representative positive Bcl-2 staining in epithelial cells of normal ovary (A), follicular cyst (B), and moderately differentiated serous papillary carcinoma (C). (Original magnification: 200x) 

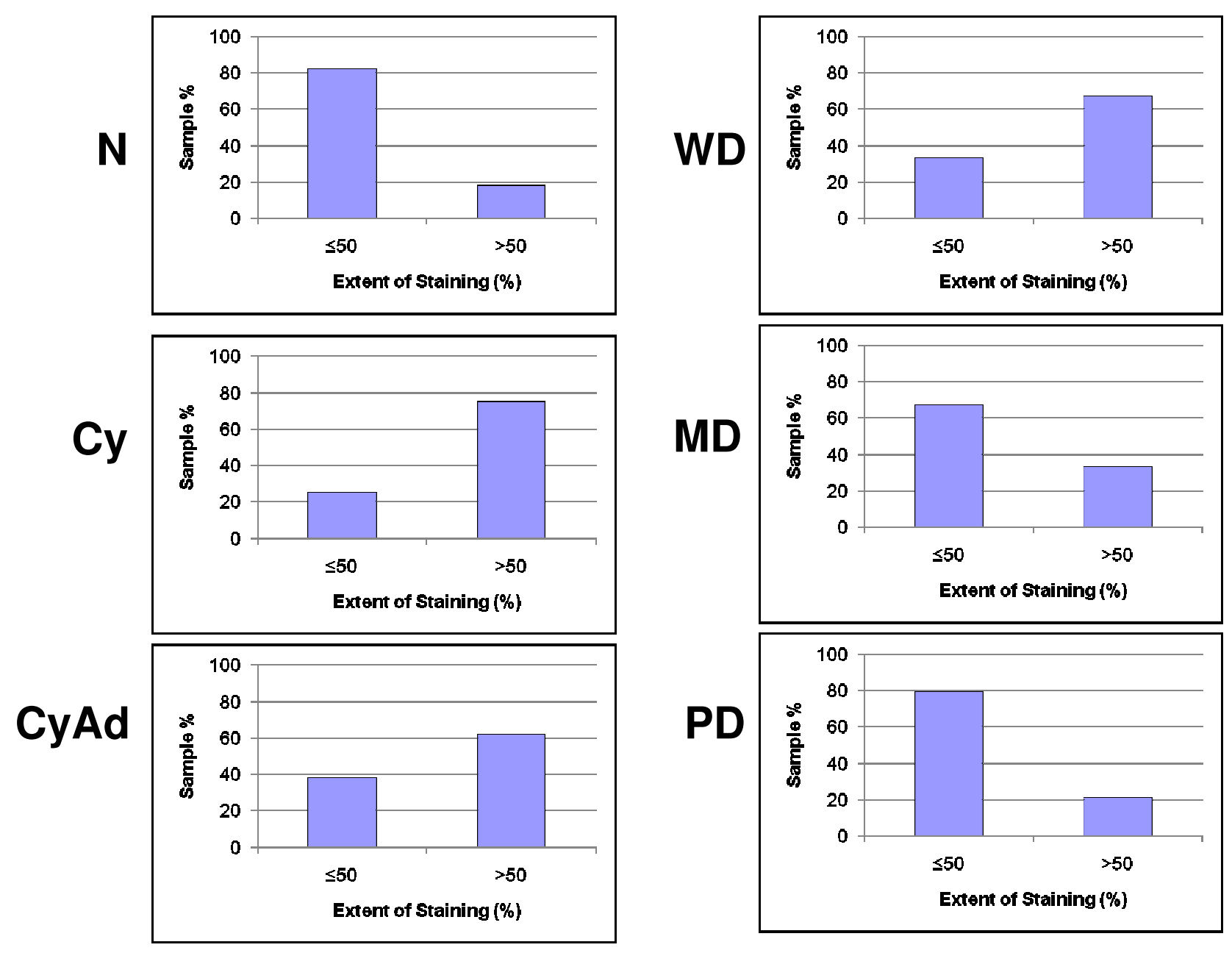

\section{Figure 2}

Extent of epithelial Bcl-2 staining decreases with tumor progression. Extent of epithelial Bcl-2 staining was observed in each section of normal (N), cyst (Cy), cystadenoma (CyAd), well-differentiated carcinoma (WD), moderately-differentiated serous papillary carcinoma (MD), and poorly-differentiated serous papillary carcinoma (PD) ovarian tissue and categorized as either $\leq 50 \%$ or $>50 \%$ positive staining. Scored sections were graphed as a percent according to total sections of each tumor type.

of epithelial Bcl-2 staining, differences in extent of stromal Bcl-2 staining between tumor types were not statistically significant with the exception of PD samples having significantly less staining than both normal and cystadenoma samples $(P=0.1$ and 0.03 , respectively). Stromal intensity was moderate in $100 \%(2 / 2)$ of the normal tissues, and in $82 \%(14 / 17)$ benign tumors (Figure 6$)$. However, moderate stromal intensity decreased to $29 \%(8 / 28)$ in ovarian cancer sections (Figure 6). Stromal Bcl-2 intensity in cystadenomas was significantly different versus intensity in $\mathrm{MD}$ and $\mathrm{PD}$ specimens $(\mathrm{P}=0.003$ and $\mathrm{P}<$ 0.0001 , respectively), while stromal $\mathrm{Bcl}-2$ intensity in cysts was not significantly different from any of the specimens. Likewise, stromal intensity decreased with increased tumor grade with 100\% (3/3) WD, 17\% (1/6)
MD, and 21\% (4/19) PD displaying moderate stromal intensity for Bcl-2 staining (Figure 6). Additionally, PD stromal intensity was significantly lower than $\mathrm{MD}(\mathrm{P}=$ 0.05).

In contrast, the average number of lymphocyte nests (defined as aggregates of 10 or more lymphocytes) (Figure 7 , Table 3) present per section increased with malignant progression. While normal and benign samples both averaged less than two lymphocyte nests per section, WD sections averaged 3.33 lymphocyte nests per section, and higher grades displayed significantly more lymphocyte nests with $\mathrm{MD}(\mathrm{P}=0.01)$ and $\mathrm{PD}(\mathrm{p}=0.003)$ sections having averages of 7.67 and 7.84 lymphocyte nests per section, respectively. Due to small sample sizes within tissue 

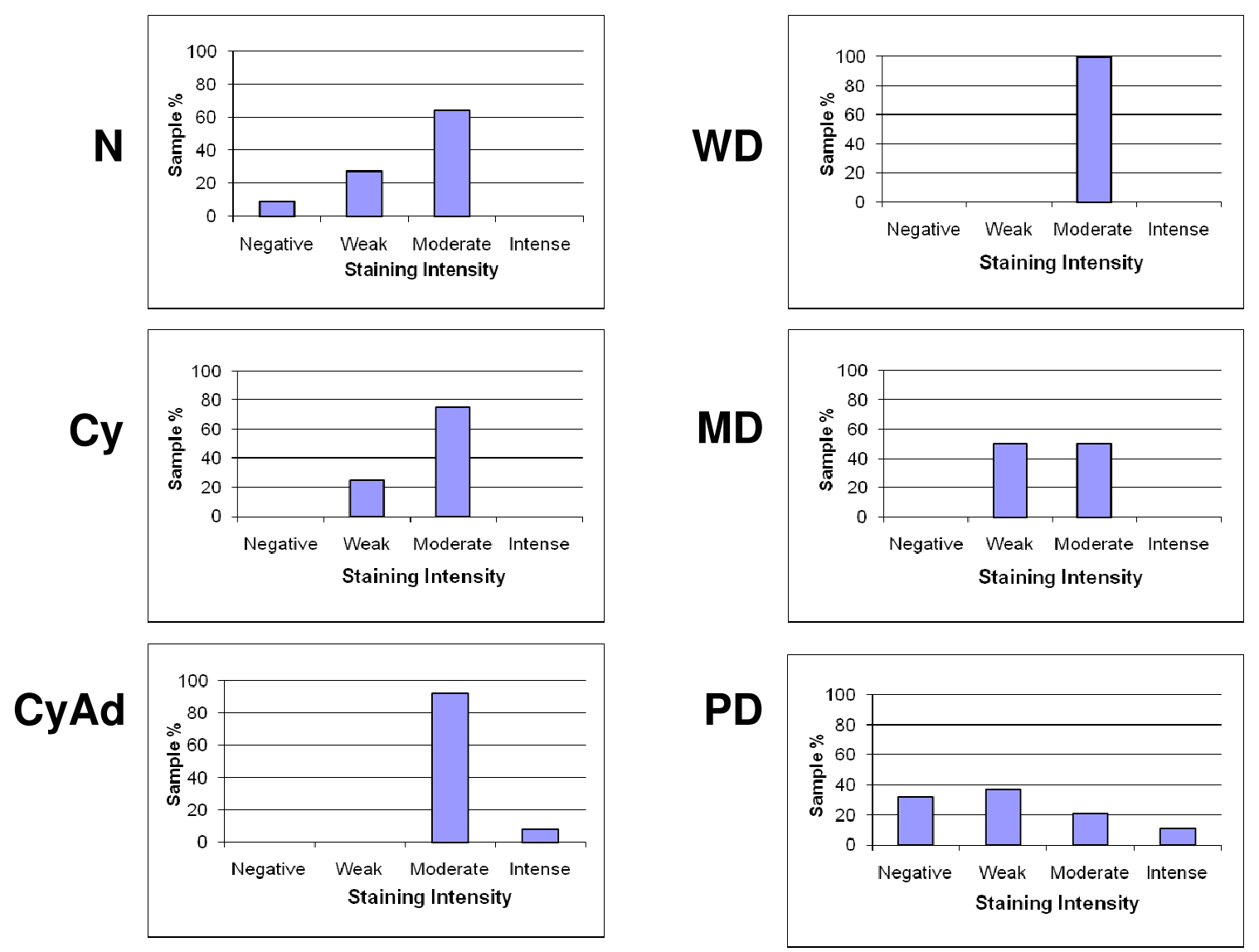

\begin{abstract}
Figure 3 according to total sections of each tumor type.

subtypes, the samples were divided simply into normal, benign, or cancerous to analyze differences in the sizes of lymphocyte nests (Table 3). Interestingly, the size of lymphocyte nests also significantly increased as tumors became cancerous $(\mathrm{p}=0.004)$. Additionally, lymphocyte population may also be associated with cancer stage because the stage I and II ovarian cancer sections did not contain any lymphocyte nests and, with the exception of one stage III cancer specimen, the stage IV cancer specimen had the highest amount of nests that contained $>100$ lymphocytes (data not shown).
\end{abstract}

Intensity of epithelial Bcl-2 staining decreases with tumor progression. Intensity of epithelial Bcl-2 staining was observed wholly in each section of normal (N), cyst (Cy), cystadenoma (CyAd), well-differentiated carcinoma (WD), moderately-differentiated serous papillary carcinoma (MD), and poorly-differentiated serous papillary carcinoma (PD) ovarian tissue and categorized as having negative, weak, moderate, or intense staining. Scored sections were then graphed as a percent

\section{Discussion}

While there have been several studies examining Bcl-2 expression with ovarian tumor progression or the prognostic importance of the presence of lymphocytes for clinical outcome in ovarian cancer, our study is the first to examine Bcl-2 expression in both epithelial and stromal cells as well as lymphocyte distribution with ovarian cancer progression. In agreement with previous studies [2022] we found that over $50 \%$ of ovarian cancers stained for $\mathrm{Bcl}-2$, but we also detected Bcl-2 staining in normal and benign ovarian specimens. Further, epithelial Bcl-2 staining was greater in normal and benign ovarian specimens compared with cancer specimens. This is in agreement with other studies [23-25] which reported greater Bcl-2 expression in normal and benign specimen compared to cancer samples. Chan et al. [23] proposed that decreased $\mathrm{Bcl}-2$ expression with tumor progression resulted from the dysregulation of Bcl-2 normally required to maintain physiological function and integrity of the normal ovarian surface epithelium. Similarly, other studies $[20,23,26]$ have reported an inverse relationship between epithelial Bcl-2 expression and tumor grade. For example, Baeke- 


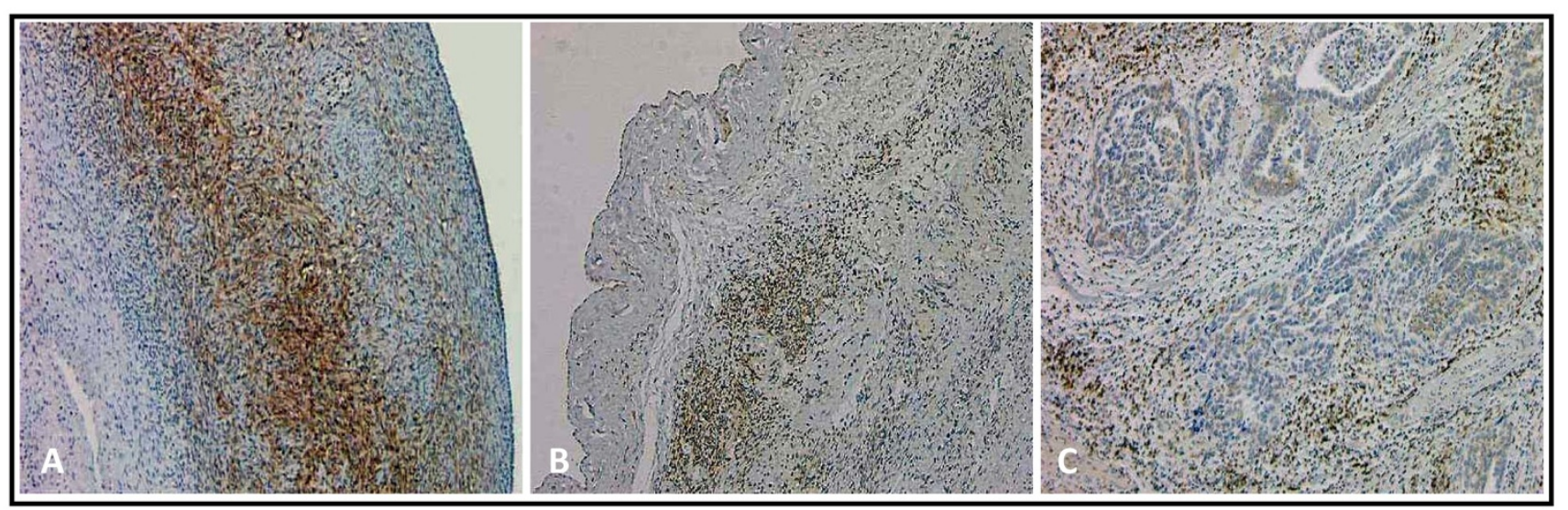

Figure 4

Stromal Bcl-2 staining decreases with tumor progression. Representative stromal Bcl-2 staining in normal ovary (A), serous cystadenoma (B), and moderately differentiated serous papillary carcinoma (C). (Original magnification: 40x)

landt et al. [27] found only 39\% of stage III epithelial ovarian carcinomas displayed immunoreactivity to $\mathrm{Bcl}-2$ in more than 5\% of the tumor cells. They did not compare these levels to $\mathrm{Bcl}-2$ expression in normal ovarian tissue, but they did conclude that $\mathrm{Bcl}-2$ expression was inversely related to tumor aggressiveness. In the present study, 57\% $(16 / 28)$ of the ovarian cancer specimens showed positive Bcl-2 staining in more than $5 \%$ of the tumor cells regardless of cancer stage. However, when only stage III ovarian cancer specimens were considered, $42 \%(8 / 19)$ of the samples demonstrated positive Bcl-2 staining in more than $5 \%$ of the tumor cells (data not shown) which is very similar to findings reported by Baekelandt et al [27]. Interestingly, we have recently reported increased levels of urinary Bcl-2 in ovarian cancer patients [28] suggesting that reduced epithelial $\mathrm{Bcl}-2$ staining with tumor progression may reflect a transition from cellular expression of $\mathrm{Bcl}-2$ to secreted Bcl-2 associated with disease progression.

Further, normal ovarian endocrine and reproductive function depends on a multifaceted and dynamic microenvironment that involves coordinated cell-cell interactions [29]. Likewise, stromal-epithelial interactions, as seen in breast carcinomas [30-32], play an important role in determining ovarian malignant progression. This is supported by the observation that ovarian surface epithelium (OSE) tumor cells are closely associated with their surrounding stromal cells [33]. Interestingly, conditioned media from normal stromal cells inhibits proliferation of SKOV3 and Caov3 ovarian cancer cell lines in vitro [29], while nude mice co-injected with SKOV3 or OCC1 ovarian cancer cells and normal stromal cells display a slower onset of tumor formation and rate of tumor growth compared to mice injected with cancer cells alone [13]. Additionally, precursors of OSE tumors, such as hyper- and metaplastic changes of the OSE and associated inclusion cysts, are related to stromal hyperplasia [34]. In the present study, we found that stromal Bcl-2 staining decreased with malignant progression and the intensity of stromal Bcl-2 expression was inversely related to tumor grade, possibly suggesting that alterations in stromal components might promote tumor progression. Taken together, these findings support a role of tumor-stromal interactions in the regulation of tumorigenesis as well as tumor progression in epithelial ovarian cancer.

Lastly, OC is a highly immunogenic disease which triggers the influx of a large number of lymphoid cells to the tumor site. Lymphocytes play a major role in the host immune response since stimulated lymphocytes release cytokines, antibodies, and growth factors necessary for immune-mediated tumor cell lysis [35]. Consequently, the presence of $\mathrm{T}$ cells is generally associated with an improved clinical outcome in advanced ovarian carcinoma. Adams et al. [36] showed that ovarian cancer patients who have tumors with a high frequency of intraepithelial $\mathrm{T}$ cells, specifically $\mathrm{CD} 8{ }^{+} \mathrm{T}$ cells, have a significantly better 5 -year survival rate than patients whose tumors have a low frequency of intraepithelial $\mathrm{CD} 8^{+} \mathrm{T}$ cells. Likewise, Clarke et al. found that the presence of intraepithelial $\mathrm{CD}^{+}$and $\mathrm{CD} 8^{+} \mathrm{T}$ cells was associated with improved survival in patients with serous ovarian carcinomas, but not patients with endometrioid or clear cell carcinomas [18]. These latter findings may be related to the presence of $\mathrm{CD}^{+} \mathrm{T}$ lymphocytes in underlying tumor stroma correlating with vascular invasion thereby potentiating tumor growth in endometrioid carcinoma [16]. In the present study, we found an increased number of lymphocyte nests with malignant transformation in ovarian specimens and the size of lymphocytes nests also 

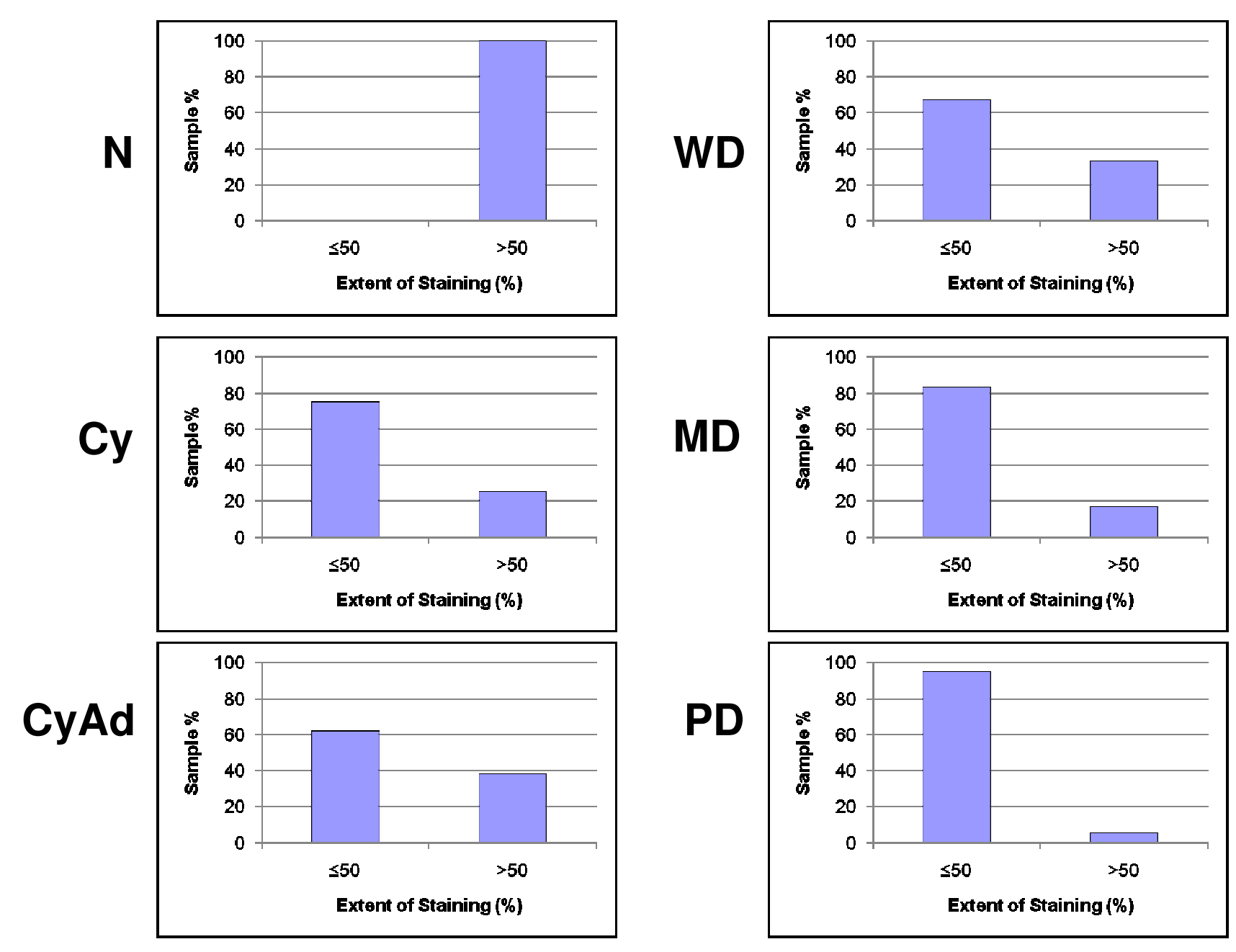

\section{Figure 5}

Extent of stromal Bcl-2 staining decreases with tumor progression. Extent of stromal Bcl-2 staining was observed in each sections of normal (N), cyst (Cy), cystadenoma (CyAd), well-differentiated carcinoma (WD), moderately-differentiated serous papillary carcinoma (MD), and poorly-differentiated serous papillary carcinoma (PD) ovarian tissue and categorized as either $\leq 50 \%$ or $>50 \%$ positive staining. Scored sections were graphed as a percent according to total sections of each tumor type.

increased significantly with tumor progression; however we did not have any information on patient survival to report any prognostic data. Given that lymphocytes secrete TGF- $\beta$ [37] which can promote mesenchymal cell growth [38], focal areas of lymphocytes, then, may support growth of higher grade ovarian tumors, especially as that pertains to ovarian epithelial cells that have undergone epithelial to mesenchymal transition characteristic of ovarian cancer progression [39]. TGF- $\beta$ is also thought to have angiogenic properties [40] which would addition- ally benefit tumor growth. Our findings of increased lymphoid aggregates present with ovarian cancer progression are in agreement with other cancers including lymphoma [41], breast cancer [42], and melanoma [43]. However, whether these lymphocytes assist in the antitumor response or promote tumor growth remains unclear since the role that they play may very well be disease-specific. 

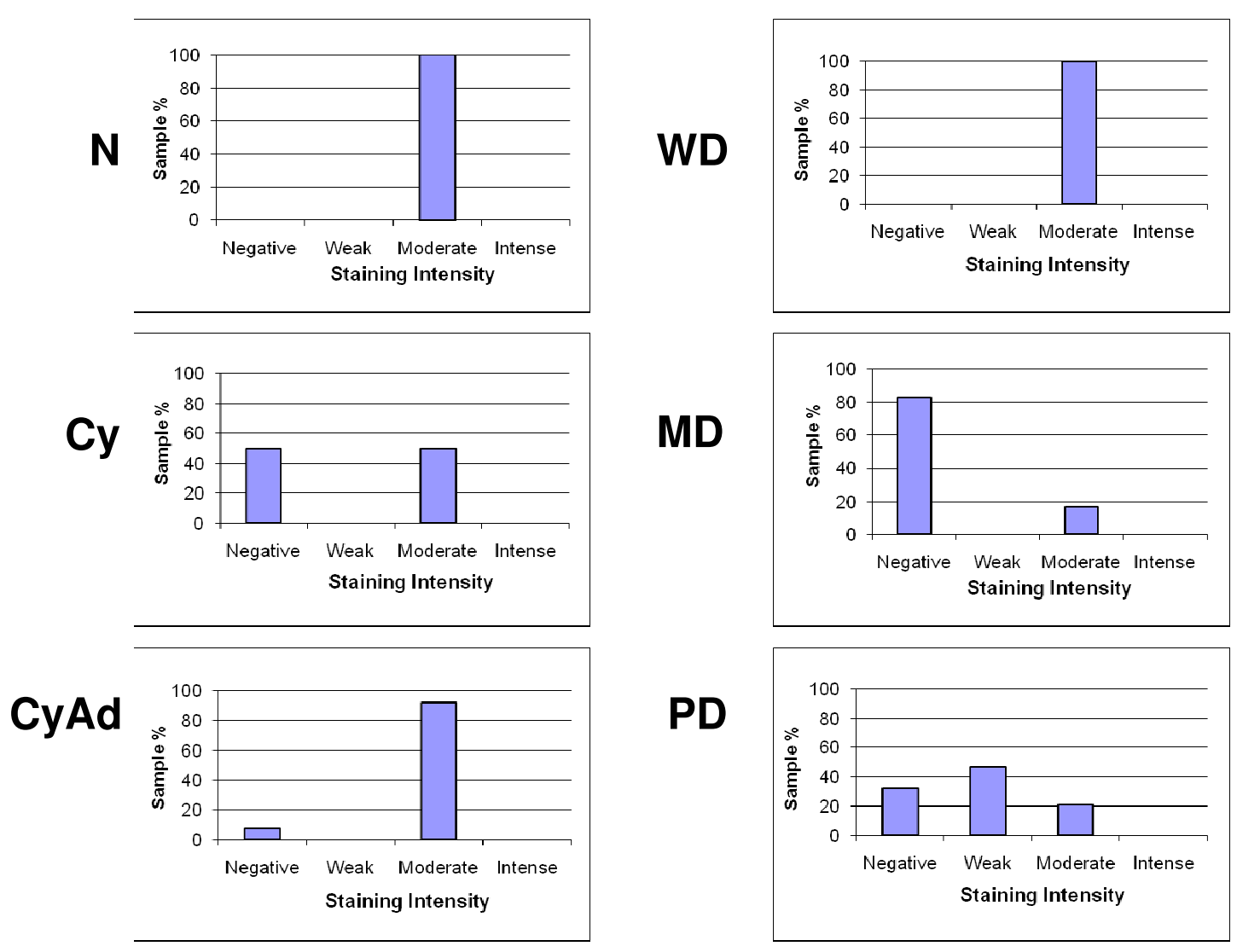

\section{Figure 6}

Intensity of stromal Bcl-2 staining decreases with tumor progression. Intensity of stromal $\mathrm{Bcl}-2$ staining was observed wholly in each section of normal (N), cyst (Cy), cystadenoma (CyAd), well-differentiated carcinoma (WD), moderately-differentiated serous papillary carcinoma (MD), and poorly-differentiated serous papillary carcinoma (PD) ovarian tissue and categorized as having negative, weak, moderate, or intense staining. Scored sections were then graphed as a percent according to total sections of each tumor type.

Table 3: Lymphocyte nests and number of lymphocytes in each nest according to tissue type.

\begin{tabular}{|c|c|c|c|c|c|c|c|c|}
\hline \multirow[t]{2}{*}{ Tumor Type } & \multirow[t]{2}{*}{$\mathbf{n}$} & \multirow[t]{2}{*}{ \# Lymph Nests* } & \multicolumn{5}{|c|}{ \# Lymphocytes in Nests } & \multirow[t]{2}{*}{ Average Lymph Nests/Section* } \\
\hline & & & $<25$ & $25-50$ & $50-75$ & $75-100$ & $>100$ & \\
\hline Normal & 2 & 0 & 0 & 0 & 0 & 0 & 0 & 0 \\
\hline \multicolumn{9}{|l|}{ Benign } \\
\hline Cyst & 4 & 6 & I & 3 & 2 & 0 & 0 & 1.5 \\
\hline Cystadenoma & 13 & 13 & 8 & 1 & 2 & I & I & 1 \\
\hline Total Cancerous & 17 & 19 & 9 & 4 & 4 & I & I & 1.12 \\
\hline \multicolumn{9}{|l|}{ Cancerous } \\
\hline WD & 3 & 10 & I & 4 & 3 & 1 & I & 3.33 \\
\hline MD & 6 & 46 & II & 11 & 9 & 2 & 13 & 7.67 \\
\hline PD & 19 & 149 & 23 & 25 & 23 & 12 & 66 & 7.84 \\
\hline Total & 28 & 205 & 35 & 40 & 35 & 15 & 80 & 7.32 \\
\hline
\end{tabular}

*Lymph Nests $=$ aggregates of 10 or more lymphocytes

$\mathrm{WD}=$ well differentiated carcinoma, $M D=$ moderately differentiated serous papillary carcinoma, $P D=$ poorly differentiated serous papillary carcinoma 


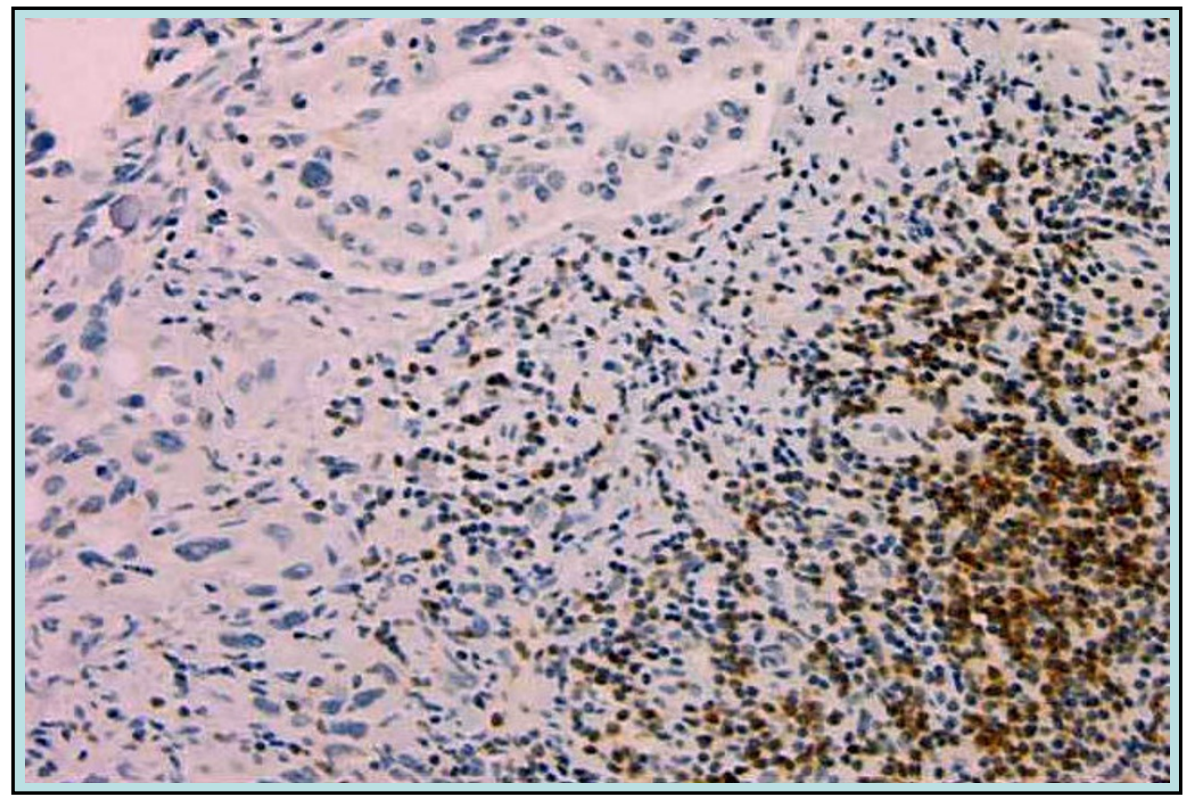

\section{Figure 7}

Lymphocyte nests are more abundant in malignant sections. Bcl-2 staining of a representative large lymphocyte nest in a poorly differentiated serous papillary carcinoma tumor. (Original magnification: 100x)

\section{Conclusion}

In this pilot study, it appears that alterations in $\mathrm{Bcl}-2$ expression and the number of lymphocytes may be to be correlated with ovarian cancer progression. Clearly, then, further studies with additional samples are warranted since, the combination of $\mathrm{Bcl}-2$ expression and lymphocyte status may be important for prognostic outcome or provide useful targets for therapeutic intervention in patients with epithelial ovarian cancer.

\section{Competing interests}

The authors declare that they have no competing interests.

\section{Authors' contributions}

PAK, SVN, NSA, and LT reviewed and analyzed immunohistochemistry sections while NSA and LT prepared the figures. NSA contributed to writing of the manuscript. SL performed immunohistochemistry. SVN procured specimens and verified de-identified histologic diagnoses and clinical information. RC performed statistical analyses. PAK developed and oversaw the project from its planning through execution and preparation of this manuscript. All authors read and approved the final version of the manuscript.

\section{Acknowledgements}

This research was supported, in part, by a US Army Department of Defense Award \#W8IXWH-07-I-0276 to PAK and a McKnight Predoctoral Fellowship from the Florida Education Fund to NSA.

\section{References}

I. Jemal A, Siegel R, Ward E, Hao Y, Xu J, Murray T, Thun MJ: Cancer statistics, 2008. CA Cancer J Clin 2008, 58(2):7I-96.

2. Williams TI, Toups KL, Saggese DA, Kalli KR, Cliby WA, Muddiman DC: Epithelial ovarian cancer: disease etiology, treatment, detection, and investigational gene, metabolite, and protein biomarkers. J Proteome Res 2007, 6(8):2936-2962.

3. Auersperg N, Maines-Bandiera SL, Dyck HG: Ovarian carcinogenesis and the biology of ovarian surface epithelium. J Cell Physiol 1997, 173(2):26|-265.

4. Piek JM, van Diest PJ, Verheijen RH: Ovarian carcinogenesis: an alternative hypothesis. Adv Exp Med Biol 2008, 622:79-87.

5. Salvador S, Gilks B, Kobel M, Huntsman D, Rosen B, Miller D: The fallopian tube: primary site of most pelvic high-grade serous carcinomas. Int J Gynecol Cancer 2009, 19(1):58-64.

6. Nicosia SV, Nicosia RF: Neoplasms of the ovarian mesothelium. In Pathology of Human Neoplasms Edited by: Azar HA. New York: Raven Press; 1988.

7. Auersperg N, Maclaren IA, Kruk PA: Ovarian surface epithelium: autonomous production of connective tissue-type extracellular matrix. Biol Reprod I99|, 44(4):717-724.

8. Bhowmick NA, Moses HL: Tumor-stroma interactions. Curr Opin Genet Dev 2005, I 5(I):97-101.

9. Barcellos-Hoff MH, Medina D: New highlights on stroma-epithelial interactions in breast cancer. Breast Cancer Res 2005, 7(I):33-36.

10. Bosman FT, de Bruine A, Flohil C, Wurff A van der, ten Kate J, Dinjens WW: Epithelial-stromal interactions in colon cancer. Int J Dev Biol 1993, 37(1):203-2II.

II. Cintorino M, Bellizzi de Marco E, Leoncini P, Tripodi SA, Xu LJ, Sappino AP, Schmitt-Graff A, Gabbiani G: Expression of alphasmooth-muscle actin in stromal cells of the uterine cervix during epithelial neoplastic changes. Int J Cancer |99|, 47(6):843-846.

12. Hayward SW, Rosen MA, Cunha GR: Stromal-epithelial interactions in the normal and neoplastic prostate. $\mathrm{Br} J$ Urol 1997, 79(Suppl 2): 18-26.

13. Parrott JA, Nilsson E, Mosher R, Magrane G, Albertson D, Pinkel D, Gray JW, Skinner MK: Stromal-epithelial interactions in the 
progression of ovarian cancer: influence and source of tumor stromal cells. Mol Cell Endocrinol 200I, I 75(I-2):29-39.

14. Pritchett TR, Wang JK, Jones PA: Mesenchymal-epithelial interactions between normal and transformed human bladder cells. Cancer Res 1989, 49(10):2750-2754.

15. Skirnisdottir I, Seidal T, Gerdin E, Sorbe B: The prognostic importance of p53, bcl-2, and bax in early stage epithelial ovarian carcinoma treated with adjuvant chemotherapy. Int J Gynecol Cancer 2002, I 2(3):265-276.

16. Kondratiev S, Sabo E, Yakirevich E, Lavie O, Resnick MB: Intratumoral CD8+ T lymphocytes as a prognostic factor of survival in endometrial carcinoma. Clin Cancer Res 2004, I 0(13):4450-4456.

17. Zhang L, Conejo-Garcia JR, Katsaros D, Gimotty PA, Massobrio M, Regnani G, Makrigiannakis A, Gray H, Schlienger K, Liebman MN, et al:: Intratumoral T cells, recurrence, and survival in epithelial ovarian cancer. N EnglJ Med 2003, 348(3):203-2/3.

18. Clarke B, Tinker AV, Lee CH, Subramanian S, Rijn M van de, Turbin D, Kalloger S, Han G, Ceballos K, Cadungog MG, et al.: Intraepithelial $T$ cells and prognosis in ovarian carcinoma: novel associations with stage, tumor type, and BRCAI loss. Mod Pathol 2009, 22(3):393-402.

19. Sato E, Olson $\mathrm{SH}, \mathrm{Ahn}$ J, Bundy B, Nishikawa $\mathrm{H}$, Qian F, Jungbluth $A A$, Frosina D, Gnjatic S, Ambrosone C, et al:: Intraepithelial CD8+ tumor-infiltrating lymphocytes and a high CD8+/regulatory $T$ cell ratio are associated with favorable prognosis in ovarian cancer. Proc Natl Acad Sci USA 2005, I02(5 I): I8538-18543.

20. Diebold J, Baretton G, Felchner M, Meier W, Dopfer K, Schmidt M, Lohrs U: bcl-2 expression, p53 accumulation, and apoptosis in ovarian carcinomas. Am J Clin Pathol 1996, 105(3):341-349.

21. Fauvet R, Dufournet C, Poncelet C, Uzan C, Hugol D, Darai E: Expression of pro-apoptotic (p53, p2 I, bax, bak and fas) and anti-apoptotic (bcl-2 and bcl-x) proteins in serous versus mucinous borderline ovarian tumours. I Surg Oncol 2005, 92(4):337-343.

22. Herod JJ, Eliopoulos AG, Warwick J, Niedobitek G, Young LS, Kerr $D$ J: The prognostic significance of $\mathrm{Bcl}-2$ and $\mathrm{p} 53$ expression in ovarian carcinoma. Cancer Res 1996, 56(9):2178-2184.

23. Chan WY, Cheung KK, Schorge JO, Huang LW, Welch WR, Bell DA, Berkowitz RS, Mok SC: Bcl-2 and p53 protein expression, apoptosis, and p53 mutation in human epithelial ovarian cancers. Am J Pathol 2000, I 56(2):409-4I7.

24. Henriksen R, Wilander E, Oberg K: Expression and prognostic significance of Bcl-2 in ovarian tumours. Br J Cancer 1995, 72(5): $1324-1329$

25. Marone M, Scambia G, Mozzetti S, Ferrandina G, lacovella S, De Pasqua $A$, Benedetti-Panici P, Mancuso S: bcl-2, bax, bcl-XL, and bclXS expression in normal and neoplastic ovarian tissues. Clin Cancer Res 1998, 4(2):517-524.

26. Zusman I, Gurevich P, Gurevich E, Ben-Hur H: The immune system, apoptosis and apoptosis-related proteins in human ovarian tumors (a review). Int J Oncol 200I, I 8(5):965-972.

27. Baekelandt M, Kristensen GB, Nesland JM, Trope CG, Holm R: Clinical significance of apoptosis-related factors p53, Mdm2, and Bcl-2 in advanced ovarian cancer. J Clin Oncol 1999, 17(7):2061.

28. Anderson NS, Bermudez Y, Badgwell D, Chen R, Nicosia SV, Bast RC $\mathrm{Jr}$, Kruk PA: Urinary levels of $\mathbf{B c l}-2$ are elevated in ovarian cancer patients. Gynecol Oncol 2009, I I 2(I):60-67.

29. Karlan BY, Baldwin RL, Cirisano FD, Mamula PW, Jones J, Lagasse LD: Secreted ovarian stromal substance inhibits ovarian epithelial cell proliferation. Gynecol Oncol 1995, 59(I):67-74.

30. Barcellos-Hoff MH, Ravani SA: Irradiated mammary gland stroma promotes the expression of tumorigenic potential by unirradiated epithelial cells. Cancer Res 2000, 60(5): $1254-1260$.

31. Joseph H, Gorska AE, Sohn P, Moses HL, Serra R: Overexpression of a kinase-deficient transforming growth factor-beta type II receptor in mouse mammary stroma results in increased epithelial branching. Mol Biol Cell 1999, 10(4):1221-1234.

32. Kuperwasser C, Chavarria T, Wu M, Magrane G, Gray JW, Carey L, Richardson A, Weinberg RA: Reconstruction of functionally normal and malignant human breast tissues in mice. Proc Natl Acad Sci USA 2004, I 0 I(14):4966-497I.

33. Hooff $A$ van den: Stromal involvement in malignant growth. Adv Cancer Res 1988, 50:159-196.

34. Resta L, Russo S, Colucci GA, Prat J: Morphologic precursors of ovarian epithelial tumors. Obstet Gynecol 1993, 82(2): I8I-I86.
35. Berek JS, Hacker NF, Hengst TC: Practical Gynecologic Oncology. 4th edition. Philadelphia: Lippincott Williams and Wilkins; 2004.

36. Adams SF, Levine DA, Cadungog MG, Hammond R, Facciabene A, Olvera N, Rubin SC, Boyd J, Gimotty PA, Coukos G: Intraepithelial $T$ cells and tumor proliferation: impact on the benefit from surgical cytoreduction in advanced serous ovarian cancer. Cancer 2009, I I 5(I3):289 I-2902.

37. Kehrl JH: Transforming growth factor-beta: an important mediator of immunoregulation. Int J Cell Cloning I99I, 9(5):438-450.

38. Nash MA, Ferrandina G, Gordinier M, Loercher A, Freedman RS: The role of cytokines in both the normal and malignant ovary. Endocr Relat Cancer 1999, 6(1):93-107.

39. Ahmed N, Thompson EW, Quinn MA: Epithelial-mesenchymal interconversions in normal ovarian surface epithelium and ovarian carcinomas: an exception to the norm. J Cell Physiol 2007, 2 I 3(3):58I-588.

40. Roberts AB, Sporn MB, Assoian RK, Smith JM, Roche NS, Wakefield LM, Heine UI, Liotta LA, Falanga V, Kehrl JH, et al.: Transforming growth factor type beta: rapid induction of fibrosis and angiogenesis in vivo and stimulation of collagen formation in vitro. Proc Natl Acad Sci USA 1986, 83( I 2):4I67-4I7I.

41. Mueller A, O'Rourke J, Chu P, Chu A, Dixon MF, Bouley DM, Lee A Falkow S: The role of antigenic drive and tumor-infiltrating accessory cells in the pathogenesis of helicobacter-induced mucosa-associated lymphoid tissue lymphoma. Am J Pathol 2005, I67(3):797-8।2.

42. Sheu BC, Kuo WH, Chen RJ, Huang SC, Chang KJ, Chow SN: Clinical significance of tumor-infiltrating lymphocytes in neoplastic progression and lymph node metastasis of human breast cancer. Breast 2008, 17(6):604-610.

43. Hussein MR, Elsers DA, Fadel SA, Omar AE: Immunohistological characterisation of tumour infiltrating lymphocytes in melanocytic skin lesions. J Clin Pathol 2006, 59(3):316-324.
Publish with Biomed Central and every scientist can read your work free of charge

"BioMed Central will be the most significant development for disseminating the results of biomedical research in our lifetime. "

Sir Paul Nurse, Cancer Research UK

Your research papers will be:

- available free of charge to the entire biomedical community

- peer reviewed and published immediately upon acceptance

- cited in PubMed and archived on PubMed Central

- yours - you keep the copyright

Submit your manuscript here:

http://www.biomedcentral.com/info/publishing_adv.asp
BioMedcentral 